\title{
The Impact of Service Quality and Cultural Beliefs on Intention to Use Financial Services: The Moderating Role of Trust
}

\author{
Khaled Mohammed Alqasa ${ }^{1} \&$ Hamad Balhareth $^{2}$ \\ ${ }^{1}$ School of Business Management, Universiti Utara Malaysia, Malaysia. University of Aden, Yemen \\ ${ }^{2}$ University of Hail, College of Business Administration, Saudi Arabia \\ Correspondence: Ebrahim Mohammed Al-Matari, School of Accountancy (SOA), College of Business (COB), \\ Universiti Utara Malaysia (UUM), Malaysia, Amran University, Yemen. E-mail: ibrahim_matri7@yahoo.com
}

\author{
Received: January 3, 2015 Accepted: February 2, 2015 Online Published: July 6, 2015 \\ doi:10.5539/ass.v11n21p20 URL: http://dx.doi.org/10.5539/ass.v11n21p20
}

\begin{abstract}
In the context of developed countries and in several Middle Eastern countries, the problem of motivating consumers to make use of banking services has been resolved. However, in Yemen, majority of the citizens are non-bank users. This fact leads to a major issue and negatively affects the economy of the country. In this regard, the present study aims to shed a light on the factors that have the potential to influence Yemeni citizen's use of the country's banking system like service quality and Yemeni culture. For this purpose, 850 questionnaires were distributed to part-time university going students. Data collected was analyzed with the help of correlation and multiple regression analysis to determine the factors prediction of the behavioral intention to use Yemeni banking system. The results showed the positive and significant effect of service quality and the significant and negative effect of culture on the consumers' use of Yemeni banking system. Moreover, hierarchical regressions were used to test the effect of trust as a moderator variable. Student's trust had a statistically moderating the relationship between cultural belief and intention but in the negative direction. The study contributes to the academic understanding of the behavioral intention of consumers in the context of Yemen and to the practitioners and policy makers use of the effective strategy to attract customers to the country's banking system.
\end{abstract}

Keywords: service quality, cultural beliefs, financial services, trust, behavioral intention

\section{Introduction}

A country's requires a reliable banking system as it is one of the primary resources that facilitate investments. The banking system is deemed by economists as the core of the country's economy as it brings about economic stability and dynamics, and in turn, it drives exchange, production and investment (Adamu \& Adeola, 2012) More importantly, a banking system is as strong as the number of people supporting it or using financial services (depositors and investors) and banks with ample numbers of customers are more able to help the economy owing to the considerable deposits for investment (Allen \& Carletti, 2008) In this regard, majority of citizens in Yemen are distrustful of the country's banking system and thus many refuse to use the system for their financial transactions.

The Yemeni banking system mechanism mirrors those existing in several Middle Eastern countries with the difference being the Yemeni system has been facing countless of challenges in the recent years that influenced economic aspects. One of these challenges is the lack of consumers using the banking system. Specifically, based on several reports, citizens with bank accounts constitute less than $4 \%$ of the population and this negatively impacts the economy of the country (Swidi \& Mahmood, 2011).

This unresolved issue minimizes the banks performance and their support of the economy. The economy of Yemen is referred to as a cash economy in that majority of the citizens prefer to deal in cash in their transactions - even while buying durable goods requiring significant amount of cash (Al-Mushrqui, 2008).

Based on the statement of one of the executives in the Central Bank of Yemen, in the past, financial authorities largely ignore the importance of attracting more consumers to use the banking system and hence, banks failed to encourage depositors to make use of their services in order to facilitate money circulation throughout the banking sector (Aladhi, 2009). This might be one of the reasons why less than $4 \%$ of the population takes advantage of banking services and why the Yemeni banking system is too weak to support its economy. 
Additionally, the lack of bank consumers is attributed to low banking culture of among the country's citizens. The citizens are either unaware of the advantages of the services or they are skeptical of using such services because of issues concerning safety and security (Aladhi, 2009). Banking services are still new to Yemeni citizens and this explains why majority of them prefer to keep their money at home (Alqasa, 2013).

\section{Literature Review}

\subsection{Banking Services Purchasing Behavior}

The effective and efficient running of a country's economy calls for an effective banking system as banking services significantly contributes to the country's various sectors. In other words, the industries are considerably reliant on the banking system's strength and durability (Hussein \& Omran, 2003).

In this background, although marketers have been attempting to understand consumers' behavior, information concerning consumers' use of financial services is still lacking. In the banking industry, consumer behavior is considered to be a very complex phenomenon. It is a dynamic aspect that requires constant examination. While a consumer would reach to certain decisions easily, sometimes critical decisions take time as it needs deep thinking. This may happen when risk is involved when selecting among options (Gaur, 2006).

In other words, understanding the purchase behavior of consumers is a critical step in attracting and retaining consumers in the banking sector. This attraction will maximize the number of bank customers and the opportunity for the economy to succeed and develop. This supports the contention that bankers should understand consumer purchase behavior towards banking services. In addition to this, consumer purchase behavior is also a topic of crucial significance to monetary authorities that can benefit from understanding it. For instance, through this understanding, the government can create strategies that motivate and encourage consumers to take advantage of the country's banking system services (Hamin \& Elliot, 2006).

\subsection{Perceived Service Quality and Behavioral Intention}

In the context of the service industry, service quality has become one of the top issues, particularly in the dynamic and competitive marketing of the banking services. Service quality is what sets a bank aside from its counterparts (Pont \& McQuilken, 2002), where the services offered should go over the expectations of consumers (Gill, Flaschner, \& Shachar, 2006).

Along the same line of contention, service quality holds the key to the banking industry's success and survival. It has been considered to be a crucial determinant of the intention of the consumers to make use of financial services and hence, its extensive examination in literature (Patricio, Fisk, \& Cunha, 2003). Several prior studies showed that poor services lead to bank switching (Garland, 2005). Specifically, Schmidt, Bergsiek and Kolesnikova (2008) reported that in the U.S., $40 \%$ of consumers switched banks owing to ineffective services. Similarly, Allred and Addams (2000) also reported that $50 \%$ of their total respondents switched banks owing to issues regarding service.

The quality-intention to use products relationship has been investigated in literature, and quality was reported to antecede consumer's behavioral intention (Gottlieb, Brown, \& Drennan, 2011) where positive perceptions of service quality was known to be related to service/product use via intention to use. Contrastingly, negative perceptions of it lead to lack of intention to purchase service/product (Kouthouris \& Alexandris, 2005).

\subsection{Culture and Behavioral Intention}

Culture regulates the behavior of individuals automatically and naturally and this is why its influence on personal behavior is considered a given. The difference in behavior towards a specific action is highlighted upon exposure to different cultural beliefs and at that point, it is realized that culture shapes behavior (Alqasa, 2014).

Several studies have been dedicated to the examination of the cultural belief's influence on consumer purchase intention, where the primary objective is to provide an insight in the people's behavioral pattern in different groups. For instance, Jung and Kau (2004) found that differences in consumers' behavior are based on their cultural belief. However, mixed findings were reported in literature concerning the influence of culture on behavior intention. Some found cultural belief's influence on consumers' behavioral intention towards a particular service/product to be positive and significant (Alqasa, Md Isa, \& Siti, 2013), others found it to be negative and significant, while some others found it to be insignificant depending on the culture of the society (Teng \& Laroche, 2007).

Back to the context of Yemen, consumers have never been inclined to the banking services as a mechanism for saving, financing or investing. People steer clear of opening bank accounts unless they really have to and they refuse to maintain a bank account unless it is unavoidable (Yemen Times Staff, 2008). 
In other words, Yemeni consumers prefer to save their money in their houses. One of the reasons for this phenomenon is that fact that dealing with banking services is still new to the Yemeni culture. Hence, it is important for banks to expend efforts to modify potential consumers' attitude for their benefit. Efforts have to be increased as consumers confidence in banks has already been tarnished following the bankruptcy incident of the Watani Bank in 2006 (Aladhi, 2009). This motivated the researchers, through the present study, to provide an insight in the influence of Yemen's cultural belief on the use of banking services among university students.

\subsection{Student's Trust (Moderator)}

Trust in general means that a person is willing to take a risk, or expose himself, in relation to somebody else (Svensson, 2005). In addition, trust is an influential element in many social interactions that engage uncertainties and dependency (Esmaili et al., 2011). That means trust is referred to the people's intention to act in a certain way. This kind of action reflects the confidence of one party on the other (Geyskens et al., 1996; Olmos, 2011). In addition, it refers to a person's expectation, beliefs or assumption about the possibility of other future actions to be favorable, beneficial, or at least not detrimental to person's interests.

Generally, trust is a key factor in many social interactions that engage dependency and uncertainties. Banking services are not only described by ambiguity, but they also are described as vulnerable to crisis, lack of control and exposure to financial difficulties or default to pay their debts .All these factors have raised the important role of risk and trust on banks.

Higher level of trust among the university students reflects a higher possibility of using banking services and vice versa. Baron and Kenny (1986) reported that a moderator affects the direction or strength of the relationship between IV and DV variables. The relation in this context between an independent and dependent variables differs owing to the function of the moderator variable. Trust is viewed as a significant variable because of its ability to moderate risk in the consumer behavior process and it allows the consumer to make risk estimation of what could happen as a result of a specific decision, or the benefit that may be gained (Galli \& Nardin, 2002).

\section{Research Framework and Methodology}

A review of literature highlighted the factors that influence consumers' behavioral intention to using banking services. On this basis, the following conceptual framework is developed:

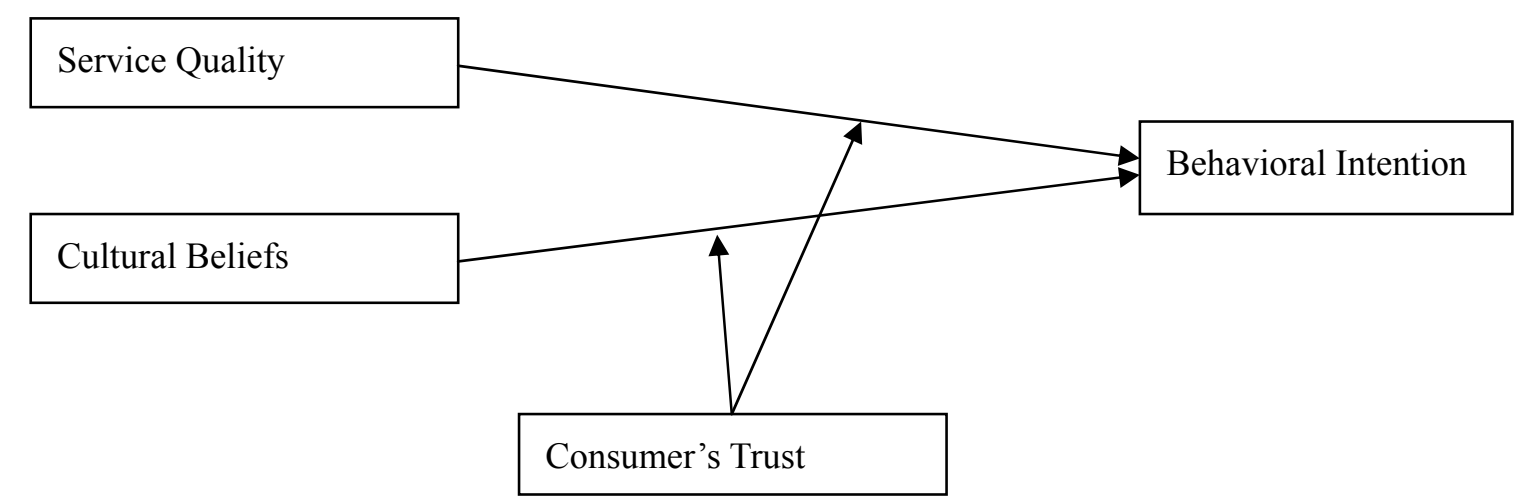

Figure 1. Theoretical framework of the study

On the basis of the above theoretical framework, the following hypotheses are proposed;

H1: There is a significant relationship between perceived service quality and student's behavioral intention to use bank services.

H2: There is a significant relationship between cultural belief and student's behavioral intention to use bank services.

H3: The relationship between service quality and behavioral intention to use bank services is moderated by student's trust.

H4: The relationship between cultural belief and behavioral intention to use bank services is moderated by student's trust. 


\subsection{Data Analysis}

Data was collected through systematic random sampling method from university students via questionnaire. From 850 questionnaires, 598 were retrieved and hence, the response rate equals to $70.4 \%$. The questionnaire items were measured through a five-point Likert scale that ranged from 1 representing strongly disagree, and 5 representing strongly agree.

The result of the correlation test is presented in Table 1. According to the table, the result obtained for service quality is $(\mathrm{r}=0.121, \mathrm{p}<0.05)$, cultural belief is $(\mathrm{r}=-0.511, \mathrm{p}<0.05)$, and for students' trust is $(\mathrm{r}=0.142, \mathrm{p}<0.05)$ indicating that the variables are significantly correlated with behavioral intention.

Table 1. Correlations among summated study variables

\begin{tabular}{ccccc}
\hline Variables & DV & IV1 & IV2 & Trust (Moderator) \\
\hline DV- Behavioural intention (BI) & 1 & & & \\
IV1- Service quality (SQ) & $.121^{* *}$ & 1 & & \\
IV2- Cultural Belief (CB) & $-.511^{* *}$ & -.074 & 1 & \\
Trust (Moderator) & $.142^{* *}$ & .056 & -.023 & 1 \\
\hline
\end{tabular}

** Correlation is significant at the 0.01 level (2-tailed).

* Correlation is significant at the 0.05 level (2-tailed).

In the present study, the direct influence of components on intention to use banking services was tested with the help of multiple regression analysis, the result of which is presented in Table 2. Based on the figures listed in the table, the three dimensions explained $26.8 \%$ of the behavioral intention variance. Specifically, standardized beta coefficient for service quality is significant and positive at $\left(\beta=.084^{*}, p<0.05\right)$ and thus supporting the first hypothesis. Similarly, the second hypothesis was also supported as beta for cultural belief is significant and negative at $\left(\beta-.505^{* *}, \mathrm{p}<0.05\right)$.

Table 2. Summary of multiple regression results

\begin{tabular}{cc}
\hline Independent Variables & Standardized Coefficient Beta (B) \\
\hline Service quality H1 & $.084^{*}$ \\
Cultural belief H2 & $-.505^{* *}$ \\
$\mathrm{R}^{2}$ & .26 .8 \\
Adjusted $\mathrm{R}^{2}$ & .265 \\
Sig. F Change & $0.000^{* *}$ \\
\hline
\end{tabular}

Note: ${ }^{*} \mathrm{p}<0.05,{ }^{* *} \mathrm{p}<0.01$

Dependent Variable: Behavioural intention (BI)

\section{Testing Trust as a Moderator on the Relationship between IVs and DV}

The researcher used hierarchical regression in conducting the examination of the moderating effect of student's trust on the relationship between IVs and behavioral intention.

To achieve this approach in this study, three models were used. The three Models are illustrated in Table 3.

Table 3. Model summary of the moderating effect of student's trust on IVs and DV

\begin{tabular}{ccrrc}
\hline \multirow{2}{*}{ Model } & \multirow{2}{*}{ R Square } & \multirow{2}{*}{$\begin{array}{c}\text { Adjusted } \mathrm{R} \\
\text { Square }\end{array}$} & & \multicolumn{2}{c}{ Change Statistics } \\
\hline 1 & .268 & .265 & R Square Change & Sig. F Change \\
2 & .284 & .280 & .268 & .000 \\
3 & .309 & .303 & .016 & .000 \\
& & & .025 & .000 \\
\hline
\end{tabular}

As it is seen in the summary of the model, Table 3 as well as in Table 4, all independent variables were entered into the regression equation in step 1 . Coefficient determination $\mathrm{R}$ square was found to be 0.268 indicating that 
$26.8 \%$ of behavioral intention can be explained by variables namely service quality and cultural belief. The ANOVA indicates that the model as a whole in this line is significant.

Table 4. The moderating effect of student's trust on IVs and DV (Behavioral Intention)

\begin{tabular}{cccc}
\hline Independent Variables & Standard Beta Step & Standard Beta Step & Standard Beta Step \\
& 1 & 2 & 3 \\
\hline service quality (SQ) & Beta & Beta & Beta \\
Cultural belief (CB) & $.084^{* *}$ & $.077^{* *}$ & .096 \\
Moderating variable & $-.505^{* *}$ & $-.502^{* *}$ & $-.814^{* *}$ \\
Students' trust (STR) & & & \\
Students' trust*'Attitude toward service & & $.126^{* *}$ & -.182 \\
quality & & & \\
Students' trust* Cultural belief & & & -.019 \\
R square & 0.268 & 0.284 & $-.471^{* *}$ \\
Adjusted R square & 0.265 & 0.280 & 0.309 \\
R square changed & 0.268 & 0.016 & 0.303 \\
Sig F change & 0.000 & 0.000 & 0.025 \\
\hline
\end{tabular}

** Significant at $\alpha<0.01$ level; * Significant at $\alpha<0.05$

In the subsequent step, student's trust is included as a predictor variable alongside with IV. In this model, the $\mathrm{R}$ square value seems to increase from $26.8 \%$ to $28.4 \%$ indicating a change of 0.016 , which means trust added $1.6 \%$ which is significant at $\mathrm{p}<0.01$. Finally, in step 3 the two interaction terms were entered accordingly into the model.

In the third mode, student's trust has been interacted with IV variables. In this line, the additional variance explained by the interaction terms revealed that $2.5 \%$ was found to be significant and statistically contributed as indicated by the change value of this model (000). ANOVA implies that the whole model which included both blocks of variables is significant.

Thus, from the regression equation, it can be shown that in the first step, all the predictor variables are significant and in the expected positive direction except cultural belief that was significant but in the negative way. In step two, the student trust is included as a predictor variable and as shown, the student's trust is significant $\left(\beta=.126^{* *}\right.$, $\mathrm{p}<0.01)$.

In scanning the significant column in Table 4in step three regarding interaction terms, it shows only the interaction between trust and culture made a statistically significant contribution $\left(\beta-.471^{* *}, \mathrm{p}<0.01\right)$.

\section{Discussion}

On the basis of this study's results, it is evident that service quality predicts the Yemeni consumers' perception of dealing with the banking system and that Yemeni consumers are concerned with the efficient delivery of banking services. The results show that the Yemeni consumers, represented by the University students, perceive the banks are able to efficiently provide them with services, Thus, when the consumers perceive that banking quality is according to their expectations, they are more likely have behavioral intentions to use banking services.

Nevertheless, although a positive significant perception was found, consumers may still make their decisions to use bank services on the basis of other specific variables that relate to priorities and preferences - service quality may not be the only antecedent of use. Many variables have been proposed to influence consumers' behavior intention to use banking services (Al-Hajri, 2008) and according to Esmaili et al. (2011) even though service quality is significant among Yemeni consumers, they hold other priorities to be equally significant including trust, protection, among others. This could explain the Yemeni scenario and as such, further research is required to examine other variables in order to shed sufficient light on the Yemeni consumers' behavioral intention to use banks and the factors that prevent them from availing bank services. 
In addition, based on the results of this study, cultural belief is significantly and negatively related with behavioral intention at $\left(\beta=. . .505^{* *}, \mathrm{p}<0.01\right)$, meaning to say, high cultural belief is accompanied by low use of banking services.

This result is consistent with that reported by Teng and Laroche (2007) who revealed conflicting results regarding culture influence on consumer purchasing intention. While some results regarding the culture-purchase intention are positive, others are negative depending upon the culture of the society. In a similar contention, Liu and McClure (2001) stated that customers hailing from different cultures tend to display different behaviors and intention to a specific product/service.

This may explain why Yemeni citizens steer clear of interacting with banks and prefer to keep their money at home. Yemeni society is characterized by low dealings with banking services (Aladhi, 2009). Additionally, according to Mushrqui (2009), the perception of holding cash in hand while dealing with financial interactions forms confidence among people and thus most trading transactions are conducted by cash, even when dealing with expensive goods.

On the other hand, the moderating effect of trust was significant on the relationship between culture and intentiondespite the negative effect. Based on the information gathered from Table 4, it was revealed that cultural belief*student's trust beta $-0.471^{* *}, \mathrm{p}<0.05$ ). Despite the opposite direction in this relationship, it displayed significant influences on student's behavioral intention. This result explains the concern that many consumers hold regarding saving their money in the Yemeni banking system, whereby they think that it is possible to take the risk and lose part of their money. This result reflects the hesitation of many Yemeni consumers to keep their money in banks due to the historical crisis in the Yemeni banking system (Yemen Times, 2008). For example, the failure of the Watani bank of Yemen to pay its debts in 2006 led to many of the bank customers losing some of their deposits and they did not get compensation from the monetary authorities. This incident may still influence consumer confidence toward dealing with banks (Aqamry, 2008).

On the other hand, culture can be a key element in forming some fundamental aspects of the consumer's behavior. Regarding this point, the culture of dealing with the banking system does not yet exist in the Yemeni society. In addition, a study conducted by the Malaysian company SIRIM Berhad (2010) reported that Yemen has a cash economy, with only $4 \%$ of the Yemeni population having bank accounts and majority of the Yemeni people deal with cash in many aspects of trading and commercial transactions (Swidi \& Mahmood, 2011). Consequently, bankers require doing a lot of effort in order to change people's attitudes towards banking services.

Despite the Islamic society, most of the banks are traditional banks and deal with interest (Reba). Due to the fact that Islamic banks entered the Yemeni financial market recently, there are only four Islamic banks to date. By looking at the Islamic banks shorter existence compared to traditional banks in Yemen, it has been reported that the Islamic banks have taken significant market shares in just a few years (Al-Hamady, 2010).In consequence, it is important for banks to exert effort to modify the attitudes of citizens towards banking services. In Yemen, the society is predominantly Islamic. It has been reported that $99.1 \%$ of the Yemeni society constitutes Muslims and they prefer to deal according to the Shariah law. But majority of the banks are convention and they deal with interest. In fact, Islamic banking activities only began in 2008 and there are only 4 Islamic banks in the country (Al-Hamdy, 2010). A close look at the lifespan of Islamic banks compared to their convention counterparts, it is evident that the former obtained significant market share over the past years indicating that people are attracted towards Islamic banks, particularly in the context of Yemen, as these banks are based on Shariah principles.

\section{Study Contributions}

Cultural belief is a crucial point in the Yemeni banking system and it could be the main factor preventing consumers' use of banking services as evident from the results. Hence, authorities should initiate an advertising campaign in an effort to modify the cultural beliefs of citizens in a positive way and make them aware of the financial services benefits. Monetary authorizes should develop a new culture of trust and confidence among potential consumers to attract more depositors to the banking institutions. Attempts should also be made by relevant parties to make the population aware of the advantages of adopting banking services for the individual, the society and the economic development and stability.

\section{Future Research}

In this study, cultural belief was revealed to have a negative effect on banking services use in Yemen. Culture is a crucial factor that shapes basic aspects of the individual's attitude. Further research is needed to examine this point in Yemen, where majority of the population (99.1\%) constitutes of Muslims. It appears that Yemeni 
citizens steer clear of using conventional banks on account of their dealings involving riba (interest), which is forbidden in Islam. This contention calls for further research.

\section{Study Limitations}

One of the limitations of this study is its context, which is Yemen wherein traditional culture is practiced in daily life. This appeared to impact the response rate of genders. Female respondents showed insufficient cooperation and provided excuses not to complete the survey. Hence, there is a gender disparity in data collection, where male respondents constitute $78.6 \%$ while female respondents only constitute $21.4 \%$ indicating the collected data's predominant male point of view.

\section{References}

Adamu, O., \& Adeola, S. (2012). A statistical evaluation of factors that attract customers to banks in Lagos, Nigeria. Global Journal of Management and Business Research, 12(3), 1-7.

Aladhi, N. (2009). Central bank of Yemen. Sana'a, Republic of Yemen.

Al-Hajri, S. (2008). The adoption of e-banking: the case of Omani banks. International Review of Business Research Papers, 4(5), 120-128.

Al-Hamady, Y. (2010). Assessment the role of the Yemeni Islamic banks in mobilizing and recruitment financial resources. Paper presented at the conference of the Yemeni Islamic banks between reality and future prospects.

Allen, F., \& Carletti, E. (2008). The roles of banks in financial systems. University of Pennsylvania and University of Frankfurt and CFS.

Allred, A., \& Addams, H. (2000). Service quality at banks and credit unions: what do their customers say? International Journal of Bank Marketing, 18(4).

Al-Mushrqui. (2009). Doing business in Yemen: A country commercial guide for U.S. Companies. U.S. Department of State.

Alqasa, K. (2013). Factors determining the purchase intention of bank services in the Republic of Yemen. Doctor of Philosophy. Universiti Utara Malaysia, January 2013.

Alqasa, K. (2014). The banking services in Yemen: Reality and challenges. Lambert academic publishing.

ALqasa, K., Isa Md, F., Norezam, S., \& Faaeq, M. K. (2013). Factors affecting intentions to use banking services in Yemen. Journal of Internet Banking and Commerce, 18(3). 1-14

AME Info. (2002). Tough times for banks in Yemen. The ultimate Middle East business resource. Retrieved November 8, 2008, from http://http://www.ameinfo.com/16688.html

Aqamry, M. (2008). End the services of 300 employees in the National Bank of Yemen. Elaph Electronic Newspaper. Retrieved July 2, 2008, from http://www.elaph.com/Web/Webform/SearchArticle.aspx?

Baron, R. M., \& Kenny, D. A. (1986). The moderator-mediator variable distinction in social psychological research: Conceptual, strategic, and statistical considerations. Journal of Penalty and Social Psychology, 51(6), 1173-1182. http://dx.doi.org/10.1037/0022-3514.51.6.1173

Esmaili, E., Desa, M., Moradi, H., \& Hemmati, A. (2011). The role of trust and other behavioural intention determinants on intention toward using internet banking. International Journal of Innovation, Management and Technology, 2(1), 95-100.

Fernández-Olmos, M. (2011). The moderating role of trust in contractual choice. British Food Journal, 113(3), 374-390. http://dx.doi.org/10.1108/00070701111116446

Galli, G., \& Nardin, G. (2002). Choice under Uncertainty: The role of trust. Faculty of Economics, University of Modena.

Gaur, S. (2006). Consumers' effortful decision making and the self- regulatory orientation (pp. 3598-3604). Indian institute of technology.

Geyskens, I., Steenkamp, J., \& Scheer, L. K. (1996). The effects of trust and interdependence on relationship commitment: a transatlantic study. International Journal of Research in Marketing, 13, 303-17. ttp://dx.doi.org/10.1016/S0167-8116(96)00006-7

Gill, A. S., Flaschner, A., \& Shachar, M. (2006). Factors that affect the trust of business clients in their banks. International Journal of Bank Marketing, 24(6), 384-405. http://dx.doi.org/10.1108/02652320610701726 
Gottlieb, U. R., Brown, M. R., \& Drennan, J. (2011). The influence of service quality and trade show effectiveness on post-show purchase intention. European Journal of Marketing, 45(11/12), 1642-1659. http://dx.doi.org/10.1108/03090561111167324

Hamin, C., \& Elliott, G. (2006). A less-developed country perspective of consumer ethnocentrism and "country of origin" effects: Indonesian evidence. Asia Pacific Journal of Marketing and Logistics, 18(2), 79-92. http://dx.doi.org/10.1108/13555850610658246

Hussein, \& Omran, M. (2003). Financial development in Arab countries. Islamic Research and Training Institute, Islamic development bank. Jeddah Saudi Arabia.

Jung, K., \& Kau, A. (2004). Culture's influence on consumer behaviour: Differences among ethnic groups in a multiracial Asian country. Advances in consumer research, 31, 366-372.

Kouthouris, C., \& Alexandris, K. (2005). Can service quality predict customer satisfaction and behavioural Intentions in the sport tourism industry? An application of the SERVQUAL model in an outdoors setting. Journal of Sport Tourism, 10(2), 101-111. http://dx.doi.org/10.1080/14775080500223165

Lees, G., Garland, R., \& Wright, M. (2005). Brand switching in New Zealand retail banking. Conference: services marketing.

Liu, R. R., \& McClure, P. (2001). Recognizing cross-cultural differences in consumer complaint behaviour and intentions: an empirical examination. Journal of Consumer Marketing, 18(1), 54-75. http://dx.doi.org/10. $1108 / 07363760110365813$

Masood, O., Niazi, G. S. K., \& Ahmad, N. (2011). An analysis of the growth and rise of smaller Islamic banks in last decade. Qualitative Research in Financial Markets, 3(2), 105-116. http://dx.doi.org/10.1108/1755417 1111155348

Patricio, L., Fisk, R. P., \& Cunha, J. (2003). Improving satisfaction with bank service offerings: Measuring the contribution of each delivery channel. Managing Service Quality, 13(6), 471-482. http://dx.doi.org/10.1108/ 09604520310506531

Pont, M., \& McQuilken, L. (2002). Testing the fit of the bankserv model to bankperf data (pp. 861-867). Conference proceedings, Melbourne, Victoria, 2-4 December 2002, Geelong, Vic., Deakin University.

Schmidt, Bergsiek, Kolesnikova. (2008). Customer preferences of financial services across the US, Germany and Russia. Journal of International Business and Cultural Studies, 1-20.

Svensson, G. (2005). Mutual and interactive trust in business dyads: condition and process. European Business Review, 17(5), 411-427. http://dx.doi.org/10.1108/09555340510620320

Teng, L., \& Laroche, M. (2007). Building and testing models of consumer purchase intention in competitive and multicultural environments. Journal of Business Research, 60(3), 260-268. http://dx.doi.org/10.1016/j. jbusres.2006.09.028

Yemen times staff. (2008). Retail banking services in Yemen: A brighter future. Retrieved June 5, 2010, from http://Yementimes.com

\section{Copyrights}

Copyright for this article is retained by the author(s), with first publication rights granted to the journal.

This is an open-access article distributed under the terms and conditions of the Creative Commons Attribution license (http://creativecommons.org/licenses/by/3.0/). 